\title{
Ginsenoside-Rb1 Induces ARPE-19 Proliferation and Reduces VEGF Release
}

\author{
Brandi S. Betts, Kalpana Parvathaneni, Bharat B. Yendluri, \\ Jeffery Grigsby, and Andrew T. C. Tsin \\ Department of Biology, The University of Texas at San Antonio, San Antonio, TX 78249, USA \\ Correspondence should be addressed to Andrew T. C. Tsin, andrew.tsin@utsa.edu
}

Received 18 October 2011; Accepted 10 November 2011

Academic Editors: A. Barak and H. Tomita

Copyright (C) 2011 Brandi S. Betts et al. This is an open access article distributed under the Creative Commons Attribution License, which permits unrestricted use, distribution, and reproduction in any medium, provided the original work is properly cited.

\begin{abstract}
$\mathrm{Rb} 1$, a ginsenoside from ginseng root extract, possesses antiangiogenic effects, but its role on ocular cells has not been studied. We hypothesize that Rb1 inhibits the production of the angiogenic cytokine VEGF from ARPE-19 cells, leading to a significant reduction in the proliferation of ocular vasculatures. Data from our experiments show that Rb1 induced an increase in the number of ARPE cells in culture, while VEGF release (pg/10,000 viable cells) was significantly reduced. Treatment with VEGF and cotreatment with Rb1 and VEGF showed that this Rb1-induced cell proliferation was mediated by VEGF. Because VEGF from RPE plays a major role in promoting angiogenesis in ocular vasculatures. Our finding that Rb1 inhibits the release of VEGF from $\mathrm{RPE}$ cells suggests that Rb1 has a significant role in the eye to protect against angiogenic diseases such as age-related macular degeneration.
\end{abstract}

\section{Introduction}

Ginseng, Panax ginseng is a popular herb with a long history of medicinal use. Chinese have used ginseng for more than a thousand years to improve energy and longevity. The genus name "Panax" was given by a Russian botanist C. A. Meyer and is derived from Greek words "pan" meaning all and "axos" meaning cure. The species name "ginseng" comes from the Chinese word "rensheng" which means "human" as ginseng roots resemble the human body [1]. In the United States, it ranks among the top five herbal products sold and is an ingredient in energy tonics and used as an immunostimulatory dietary supplement [2]. It is a potent inhibitor of angiogenesis in vivo and in vitro, however, the underlying mechanism remains unknown [3]. Ginsenosides (or ginseng saponins) represent the principle active ingredients in ginseng and more than thirty different analogues have been identified [4]. Ginsenosides, Rb1 and Rg1, are the two major active constituents of ginseng. Ginsenosides belong to a family of steroids and share structural characteristics with steroid hormones [3] such as a four-ring steroid-like structure with an attached sugar [5].
Age-related macular degeneration $(A M D)$ is a progressive eye disease which is the most common cause of irreversible vision loss and blindness in people aged 60 or older. It is characterized by angiogenesis, the abnormal growth of new blood vessels [6], which leak fluid and blood into the retina, inducing scar formation and destroying central vision. AMD is usually defined as either "dry" or "wet" and is a slow progressive disease with genetic influences as well as environmental risk factors such as cigarette smoking and perhaps diet and lifetime light exposure [7].

The retinal pigment epithelium (RPE) sustains visual function of the eye as the major metabolic gate keeper between photoreceptors in the retina and the choriocapillaries. The RPE and Bruch's membrane (BM) suffer cumulative damage over lifetime, which is thought to induce AMD in susceptible individuals [8-10]. By virtue of its location, and presence of tight junctions, RPE cells facilitate selective molecular transport between the choroidal blood and the outer neural retina, thus forming the outer blood-retina barrier (BRB) which prevents the passage of large molecules from choriocapillaries into the retina [11]. In addition, the RPE is responsible for phagocytosis and degradation of shed 
photoreceptors' outer segments. The disruption of these processes has been shown to result in retinal degeneration in experimental animal models and defects in the RPE contribute to initiation and/or progression of AMD in humans [11]. Although the vision loss of AMD results from photoreceptor damage in the central retina, the initial pathogenesis involves degeneration of RPE $[12,13]$. Central to photoreceptor survival and function, the RPE is the major source of angiogenic (e.g., vascular endothelial growth factor (VEGF)) and antiangiogenic (e.g., pigment epithelium-derived factor (PEDF)) factors and therefore plays a central role in the modulation and progression of choroidal neovascularization [14-16] leading to AMD. Therefore it is essential to understand the changes in RPE cell and their release of angiogenic cytokines to mediate the propagation of diseases such as AMD.

Vascular endothelial growth factor (VEGF) is a proangiogenic growth factor (cytokine) which contributes significantly to the pathologic neovascularization in ischemic ocular diseases such as diabetic retinopathy, persistent hyperplastic vitreous syndrome, retinopathy of prematurity and choroidal neovascularization. VEGF is the key signal used by oxygen-hungry cells to promote growth of blood vessels. VEGF is a survival factor for endothelial cells of vasculature both in vitro and in vivo. It binds to specialized receptors on the surfaces of endothelial cells and directs them to proliferate leading to new vessels [17]. Although endothelial cells are the primary target of VEGF, several studies have reported its mitogenic effects on nonendothelial cells [18]. Recent studies show that RPE barrier integrity is modulated by VEGF through apically oriented VEGF-R2 receptors and thus, there is a growing body of evidence that intraocular VEGF can increase the permeability of both the inner (as in capillary walls) and outer blood-retina barriers, contributing to the accumulation of sub-retinal fluid and macular edema [19]. VEGF-A is necessary for cell survival, but has been implicated as a key protein involved in diseases associated with angiogenesis [20].

In the present study, significant effects were observed when human ARPE-19 cells in culture were treated with different concentrations of ginsenoside $\mathrm{Rb}$. This is the first study to report Rb1-induced RPE cell proliferation and reduces VEGF release (per 10,000 viable cells). These novel findings extend the known antiangiogenic effect of ginsenosides to the ocular tissues. Extensive investigations into the role of $\mathrm{Rb} 1$ in the prevention of ocular angiogenesis could lead to new methods of prevention and treatment of vascular eye diseases such as AMD and diseases of the retina.

\section{Material and Methods}

$R b 1$ is a chemically pure saponin which is the principle ingredient of ginseng (a gift from Dr. R. N. S. Wong, Hong Kong Baptist University). Half-life of Rb1 is 16.7 hours noted in rat studies by Qian and Cai [21].

2.1. Culture of Retinal Pigment Epithelial Cells. Adult retinal pigment epithelial cells (ARPE-19) were obtained from the American Type Culture Center (ATCC—catalog number:

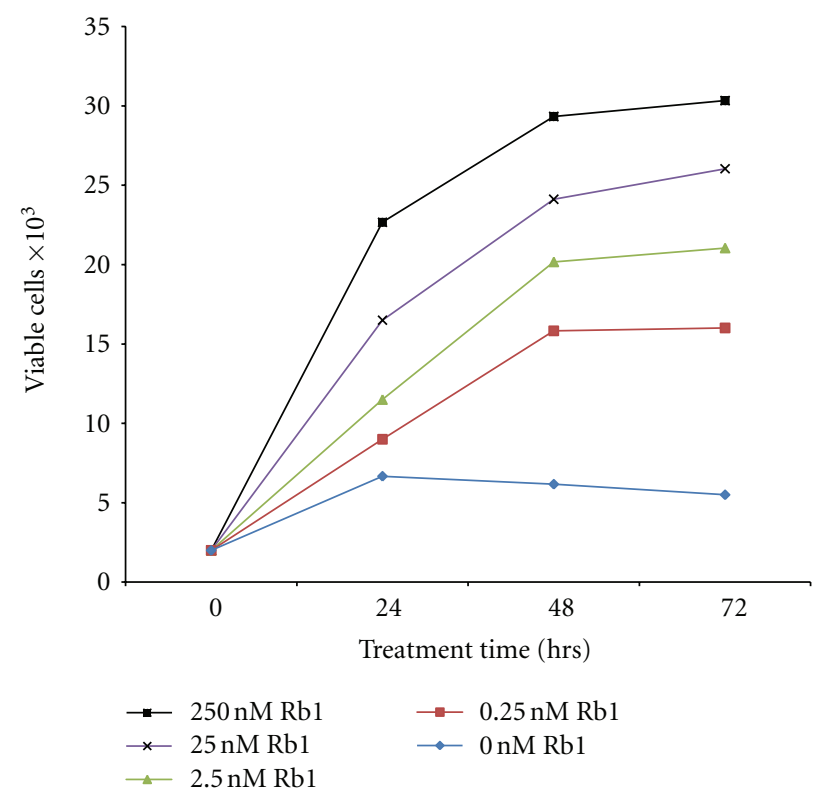

FIGURE 1: Effect of different concentrations of Rb1 on cell viability with increasing time. Cells were seeded at 20,000 per well on Day 0 . The cells were treated with $0,0.25,2.5,25$, and $250 \mathrm{nM}$ concentrations of Rb1, respectively. Cells were collected at 24, 48, and $72 \mathrm{hrs}$. Viable cells were counted using methods described previously. Media was unchanged within the $72 \mathrm{hr}$ experimental period. Results indicate mean viable cell counts \pm SE $(n=3)$.

CRL-2302). Cells were grown to confluence in Dulbecco's Modified Eagle's Medium (DMEM) containing $5.5 \mathrm{mM}$ glucose and $10 \% \mathrm{FBS}$ at $37^{\circ} \mathrm{C}+5 \% \mathrm{CO}_{2}$. Cells were seeded into 24-well plates at a density of 20,000 per well and incubated for $24 \mathrm{hrs}$ prior to serum starving and treatments.

2.2. Rb1-Induced RPE Proliferation: Time and Dose Dependency Experiments. ARPE-19 cells were cultured as described previously [14]. After serum starving for $24 \mathrm{hrs,} \mathrm{cells} \mathrm{were}$ treated with serum free media (SFM) containing 0.0, 0.25, 2.5, 25, $250 \mathrm{nM} \mathrm{Rb1}$, respectively, for $24,48,72 \mathrm{hrs}$. After 24, 48 , and $72 \mathrm{hrs}$, the conditioned media was collected and stored at $-20^{\circ} \mathrm{C}$ for cytokine determination. Cells were removed and counted using a Neubauer Hemacytometer and trypan-blue exclusion method per manufacturer's instructions.

2.3. Exogenous Treatment of VEGF on ARPE-19 Cells. ARPE19 cells were cultured as described previously and treated for $24 \mathrm{hrs}$ with SFM containing $0.006,0.06,0.6$, and $6 \mathrm{pg} / \mathrm{mL}$ of VEGF (VEGF was a generous gift from Dr. Clyde Phelix of UT, San Antonio), respectively. Cells were removed and counted using cell counting methods described previously.

2.4. Exogenous Cotreatment of VEGF and Rb1. The effect of cotreatment on cell proliferation and cytokine release by ARPE-19 cells were carried out by co-treated cells with SFM containing $250 \mathrm{nM} \mathrm{Rb1}$ and exogenous VEGF in concentrations described previously $(0.006,0.06,0.6$, and $6 \mathrm{pg} / \mathrm{mL}$ 


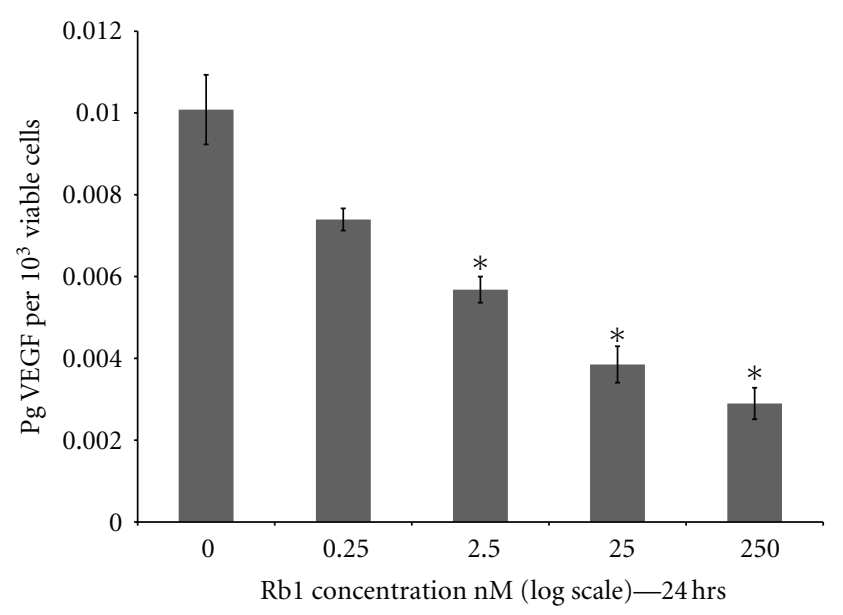

(a)

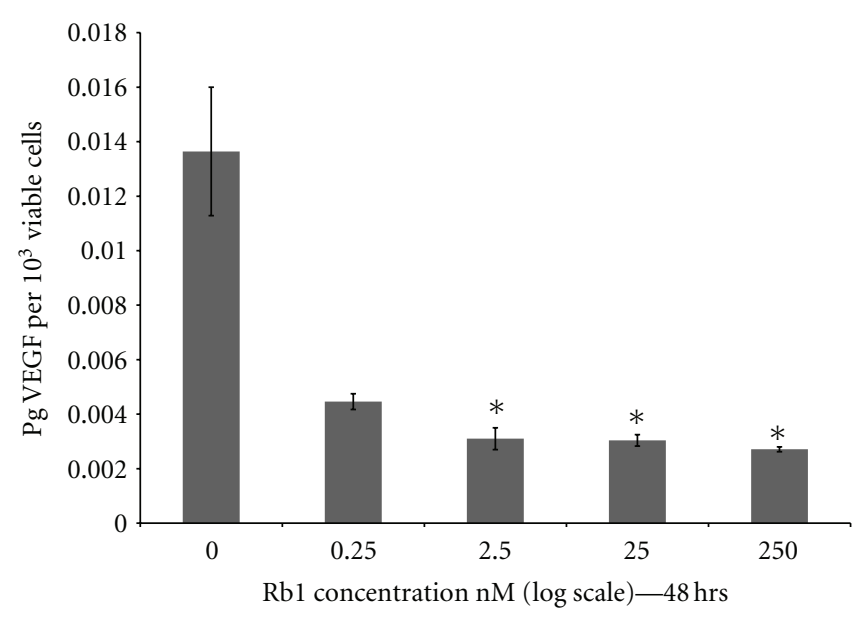

(b)

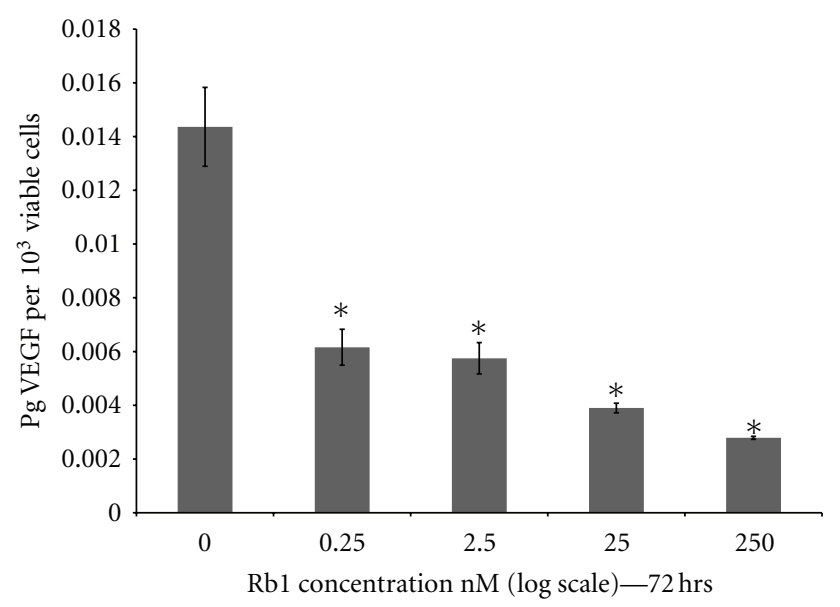

(c)

FIGURE 2: Effect of different concentrations of Rb1 on VEGF release with increasing time. Cells were seeded at 20,000 per well on day 0 . The cells were treated with $0,0.25,2.5,25$, and $250 \mathrm{nM}$ concentrations of $\mathrm{Rb} 1$ for 24,48 , and $72 \mathrm{hrs}$. Conditioned media was collected and ELISA performed for the total protein concentration for each day. The results shown in the graph indicate the mean pg of VEGF per 10,000 viable cells for the respective day \pm SE. (a), (b), and (c) are the mean pg of VEGF per 10,000 viable cells when treated with different concentrations of Rbl during the $0 \mathrm{hr}$ to $72 \mathrm{hr}$ treatment periods \pm SE. Asterisks indicate statistical significance of $P \leq 0.05(n=3)$.

of VEGF, resp.). The conditioned media was collected and stored at $-20^{\circ} \mathrm{C}$ for cytokine determination. Cells were removed and counted using cell-counting methods described previously.

2.5. Cytokine Determination. To determine the cytokine levels a quantitative sandwich Enzyme-Linked Immuno Sorbent Assay (ELISA) (Cat. number KHG0111; Invitrogen) was performed per manufacturer's instructions. The conditioned media was then used to quantify VEGF levels according to manufacturer's instructions. Absorbances were measured at $450 \mathrm{~nm}$ using a Dynex Technologies MRXII plate reader equipped with Revelation 4.25 software. Concentrations of VEGF were quantified by comparing absorbances to their respective standard curves.

2.6. Statistical Methods. Data were analyzed using oneway analysis of variance (ANOVA). A $P$ value $\leq 0.05$ is considered to be statistically significant and are indicated with "*”.

\section{Results}

3.1. Rb1-Induced ARPE-19 Cell Proliferation: Time and Dose Dependency. A 3-day-dose dependency study show there is a significant increase in viable ARPE-19 cells in response to increased concentration of $\mathrm{Rb} 1$ and incubation time. Treatment with $0,0.25,2.5,25$, and $250 \mathrm{nM}$ Rb1 resulted in cell proliferation in a dose- and time-dependent manner (Figure 1).

3.2. Rb1-Induced Downregulation of VEGF in ARPE-19 Cells in Culture. Treatment of ARPE-19 cells with increasing concentration of $\mathrm{Rb} 1(0,0.25,2.5,25$, and $250 \mathrm{nM})$ for 24,48 , and $72 \mathrm{hrs}$ resulted in a significant decrease of VEGF (pg/10,000 viable cells) in the conditioned media (Figure 2(a)). Level of VEGF in the conditioned media 


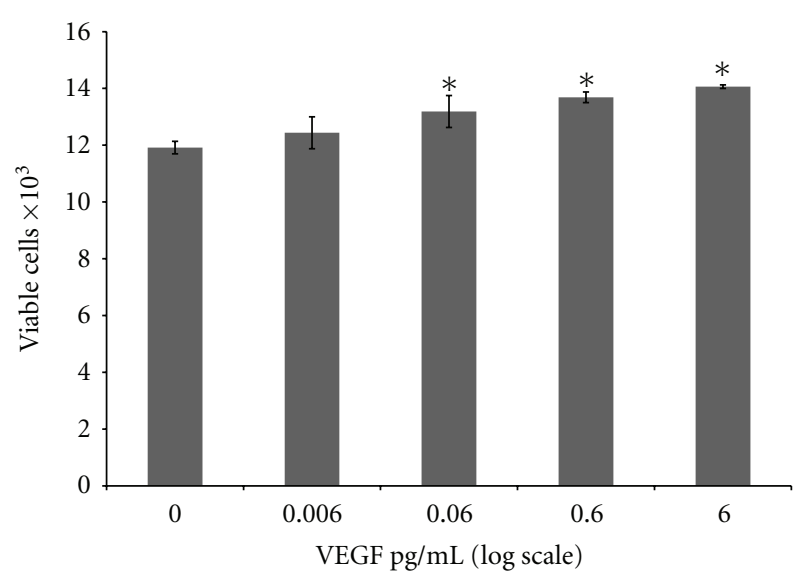

Figure 3: Effect of exogenous VEGF on cell viability. Cells were seeded at 20,000 per well on Day 0. The cells were treated with 0 , $0.006,0.06,0.6$, and $6 \mathrm{pg} / \mathrm{mL}$ concentrations of VEGF for $24 \mathrm{hrs}$. Viable cells were counted using methods described previously. Results indicate mean viable cell counts \pm SE. Asterisks indicate statistical significance of $P \leq 0.05(n=3)$.

collected at $24 \mathrm{hrs}$ decreased in proportion to increasing (log) $\mathrm{Rb} 1$ concentration. Levels of VEGF in conditioned media collected in 48 and 72 hrs were significantly lower $(30.77 \%$; $P \leq 0.05)$ when treated with $\mathrm{Rb} 1(0.25,2.5,25$, and $250 \mathrm{nM})$ when they are compared to VEGF levels in conditioned media without Rb1 (0.0 nM; Figures 2(b) and 2(c)).

3.3. Effect of Exogenous VEGF on Cell Viability. When ARPE19 cells are treated with $0.006,0.06,0.6$, and $6 \mathrm{pg} / \mathrm{mL}$ of exogenous VEFG, there is a small increase in viable cells (Figure 3 ) with significance only at $0.06,0.6$, and $6 \mathrm{pg} / \mathrm{mL}$ of VEFG.

\subsection{Effect of Exogenous VEGF and Rb1 Cotreatment on Cell} Viability. Treatment of ARPE-19 cells with $250 \mathrm{nM} \mathrm{Rb1}$ for $24 \mathrm{hrs}$ resulted in a significant increase in the number of viable cells by $58.8 \%(P \leq 0.01)$ when compared to $0.0 \mathrm{nM}$ Rb1 (Figure 4(a)). However, cotreatment with VEGF resulted in significant decrease in viable cells $(10.5 \%)$ when cotreated with $0.006 \mathrm{ng} / \mathrm{mL}$ VEGF, decrease by $13.7 \%(P \leq$ $0.05)$ when treated with $0.06 \mathrm{ng} / \mathrm{mL}$ VEGF, decrease by $20.5 \%(P \leq 0.01)$ when treated with $0.6 \mathrm{ng} / \mathrm{mL}$ VEGF and $27.8 \%(P \leq 0.01)$ when treated with $6 \mathrm{ng} / \mathrm{mL}$ VEGF, respectively, compared to $250 \mathrm{nM} \mathrm{Rb1;} \mathrm{(Figure} \mathrm{4(a)).} \mathrm{This}$ significant inhibition of Rb1-induced cell proliferation was dose dependent (Figure 4(b)).

\section{Discussion}

Although previous studies have shown that ginsenosides possess a potent antiangiogenic effect, its action on ocular cells has not been studied. Results from the present study are the first to show that Rb1, a principal active ingredient of ginseng, significantly induced human RPE cell proliferation in a time- and dose-dependent manner (Figure 1). Moreover, treatment of ARPE-19 cells with Rb1 at different concentrations for 24,48 , and $72 \mathrm{hrs}$ resulted in a significant reduction in VEGF (a known proangiogenic cytokine) levels (pg/10,000 viable cells) in the conditioned media (Figure 2), which may be a direct result of downregulation of its cellular synthesis and release. As RPE cells are located adjacent to choroidal capillaries and other major ocular vasculatures, and are the major contributor of VEGF in the eye, these finding suggests that Rb1 may have a strong effect on the inhibition of angiogenesis of choroidal and retinal capillaries, which contribute to the development of AMD and diabetic retinopathy.

Figure 3 shows that VEGF (up to $6 \mathrm{pg} / \mathrm{mL}$ for $24 \mathrm{hrs}$ ) resulted in a small increase in the number of viable cell. Figure 2(a) shows that $\mathrm{Rb} 1$ (at $250 \mathrm{nM}$ for $24 \mathrm{hrs}$ ) resulted in a significant decrease in VEGF synthesis and release (per 10,000 cells). When co-treated with VEGF $(6 \mathrm{pg} / \mathrm{mL})$ and $\mathrm{Rb} 1(250 \mathrm{nM})$ for $24 \mathrm{hrs}$, the effect of Rb1 on the increase in cell number (see Figure 1), as a result of significantly a downregulated VEGF synthesis and release (per 10,000 viable cells; Figure 2(a)), far out-weighed the effects of exogenously added VEGF ( $6 \mathrm{pg} / \mathrm{mL}$; Figure 3 ) on the small increase in cell number. Together with results that Rb1 treatment-induced cell proliferation and decreased VEGF release (Figures 1 and 2), results from ARPE-19 cells co-treated with VEGF and Rb1 (Figure 4) strongly suggest that Rbl's effect on the increase in RPE cells may be a direct result of its significant inhibition on VEGF synthesis and release by these cells.

Currently, there are few pharmacokinetic studies on the effects of ginsenosides in humans [22]. Because there is limited literature discussing plasma concentration of ginsenosides in humans, the physiological or toxic levels of ginsenoside Rb1 in human blood is unclear [23-25]. Sengupta et al. studied ginsenoside Rbl's angiogenesis effects at the concentrations of $0.125,1.25$, and $125 \mathrm{nM}$, respectively. Leung and associates used 100, 150, 250 and $500 \mathrm{nM}$ concentrations of Rb1 in HUVEC's and observed a significant decrease in tube formation following treatment with $250 \mathrm{nM}$ Rb1. Therefore, we selected $250 \mathrm{nM}$ of Rb1 for our experiments.

The particular pathways involved in how this Rb1 mediates its effects should be further studied. As ginsenosides are steroidal compounds, which are structurally similar to estrogen, it is possible that $\mathrm{Rb} 1$ binds to estrogen receptor to affect a downstream pathway. Recent investigations from our laboratory indicate that with the increasing concentration of estrogen there is a decrease in VEGF and PEDF in Rhesus monkey retinal capillary endothelial cells [26]. Further studies will be needed to investigate how Rbl exert its effect on RPE cells via estrogen receptors [3].

Retinal angiogenesis is an extensively studied, yet not fully understood process in which retinal vascular endothelial cells proliferate and migrate through a damaged vessel basement membrane and form tubules that can circulate blood [27-29] and is signaled by VEGF secretion. This neovascularization leads to impaired vision. Based on results from the present study, the ginsenoside $\mathrm{Rb} 1$ might be considered as an important homeopathic or pharmacological treatment for ocular diseases like AMD which involves the 


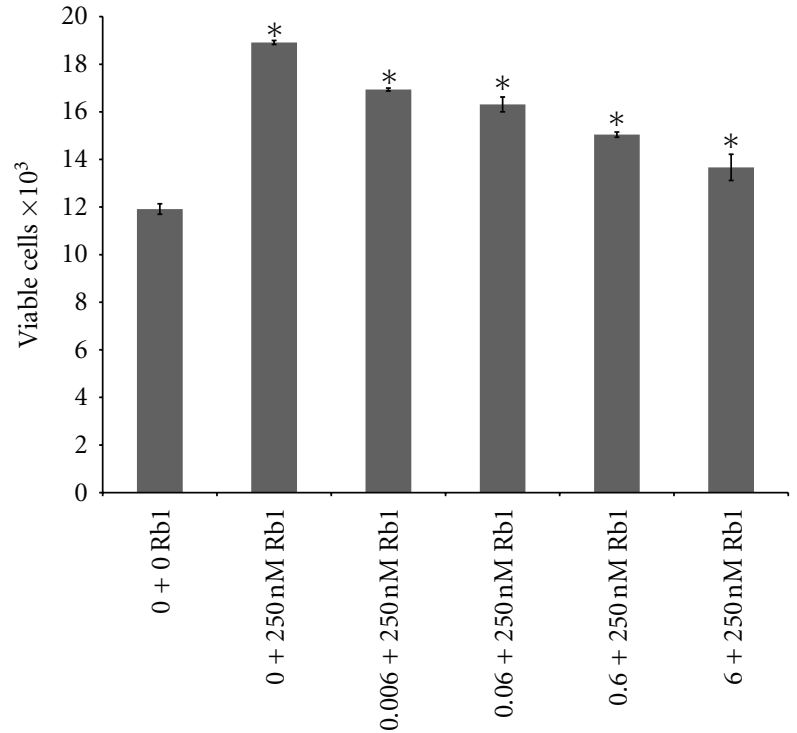

$\mathrm{pg} / \mathrm{mL}$ VEGF and $\mathrm{Rb} 1$

(a)

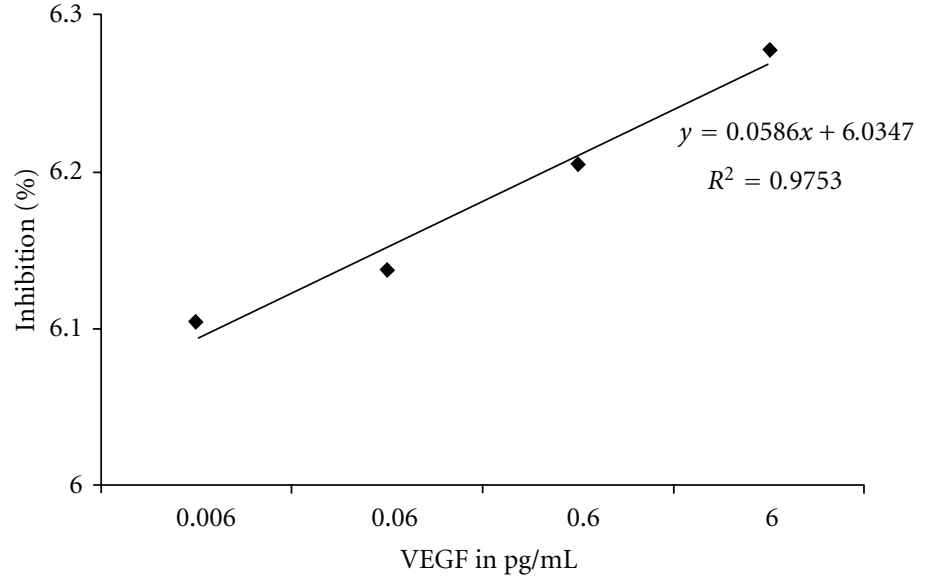

(b)

Figure 4: Effect of cotreatment of exogenous VEGF and $250 \mathrm{nM} \mathrm{Rb1}$ on cell viability. (a) Cells were seeded at 20,000 per well on Day 0. Cells were co-treated with $250 \mathrm{nM} \mathrm{Rb1}$ and $0,0.006,0.06,0.6$ and $6 \mathrm{pg} / \mathrm{mL}$ of VEGF respectively. Cells were incubated for 24 hrs and viable cell numbers were determined using methods described previously. Results indicate mean viable cell counts \pm SE. Asterisks indicate statistical significance of $P \leq 0.05(n=3)$. (b) \% Inhibition of cell viability due to the cotreatment (semi-log plot). The cell count data was compared when the cells were treated with $250 \mathrm{nM}$ Rb1 versus cotreatment with Rb1 and different concentrations of VEGF for 24 hrs. The results indicate the percentage of inhibition with the cotreatment. The \% inhibition is calculated by [viable cells with Rb1 treatment - viable cells with VEGF \& Rb1 cotreatment]/[viable cells with Rb1 treatment - viable cells with no treatment (control)] using results shown in (a).

process of choroidal neovascularization mediated by the potent angiogenic growth factors VEGF.

\section{Conclusions}

In summary, we report a significant effect of $\mathrm{Rb} 1$ on the viability of ARPE-19 cells and found that Rb1 significantly decreased cellular VEGF production, a pro-angiogenic cytokine in ARPE-19. This is the first report of antiangiogenic function of Rb1 in an important ocular cell type.

Understanding the correlation between the growth factors and their dependence on specific cell types is essential for future pharmacological studies. Rb1 is a potential antiangiogenic agent which may decrease choroidal neovascularization, thus providing a new method of intervention of AMD and other related types of angiogenic ocular diseases.

\section{Acknowledgments}

The authors thank Dr. R. N. S. Wong for providing Rb1, Dr. C. Phelix for providing VEGF. They thank the NIHNCRR-RCMI Program for financial support. They also thank Kronkosky Charitable Foundation, The San Antonio Life Sciences Institute, UTSA (CRTS, STTM, CRSGP, Biology Dept. and College of Sciences) for additional support.

\section{References}

[1] E. Nocerino, M. Amato, and A. A. Izzo, “The aphrodisiac and adaptogenic properties of ginseng," Fitoterapia, vol. 71, no. 1, pp. S1-S5, 2000.

[2] S. L. Gray, B. R. Lackey, P. L. Tate, M. B. Riley, and N. D. Camper, "Mycotoxins in root extracts of American and Asian ginseng bind estrogen receptors $\alpha$ and $\beta$," Experimental Biology and Medicine, vol. 229, no. 6, pp. 560-568, 2004.

[3] K. W. Leung, L. W. T. Cheung, Y. L. Pon et al., "Ginsenoside Rb1 inhibits tube-like structure formation of endothelial cells by regulating pigment epithelium-derived factor through the oestrogen $\beta$ receptor," British Journal of Pharmacology, vol. 152, no. 2, pp. 207-215, 2007.

[4] T. K. Yun, "Brief introduction of Panax ginseng C.A. Meyer," Journal of Korean Medical Science, vol. 16, pp. S3-S5, 2001.

[5] M. Yoon, H. Lee, S. Jeong et al., "Peroxisome proliferatoractivated receptor is involved in the regulation of lipid metabolism by ginseng," British Journal of Pharmacology, vol. 138, no. 7, pp. 1295-1302, 2003.

[6] E. Einwallner, C. Ahlers, I. Golbaz et al., "Neovascular agerelated macular degeneration under anti-angiogenic therapy: subretinal fluid is a relevant prognostic parameter," Ophthalmologe, vol. 107, no. 2, pp. 158-164, 2010.

[7] J. R. Evans, "Risk Factors for age-related macular degeneration," Progress in Retinal and Eye Research, vol. 20, no. 2, pp. 227-253, 2001.

[8] E. Bossi and F. Koerner, "Retinopathy of prematurity," Intensive Care Medicine, vol. 21, no. 3, pp. 241-246, 1995. 
[9] J. W. Miller, A. P. Adamis, and L. P. Aiello, "Vascular endothelial growth factor in ocular neovascularization and proliferative diabetic retinopathy," Diabetes/Metabolism Reviews, vol. 13, no. 1, pp. 37-50, 1997.

[10] P. G. Steinkuller, L. Du, C. Gilbert, A. Foster, M. L. Collins, and D. K. Coats, "Childhood blindness," Journal of the American Association for Pediatric Ophthalmology and Strabismus, vol. 3, no. 1, pp. 26-32, 1999.

[11] F. Q. Liang and B. F. Godley, "Oxidative stress-induced mitochondrial DNA damage in human retinal pigment epithelial cells: a possible mechanism for RPE aging and age-related macular degeneration," Experimental Eye Research, vol. 76, no. 4, pp. 397-403, 2003.

[12] W. R. Green, "Histopathology of age-related macular degeneration," Molecular vision, vol. 5, p. 27, 1999.

[13] C. W. Spraul, G. E. Lang, and H. E. Grossniklaus, "Morphometric analysis of the choroid, Bruch's membrane, and retinal pigment epithelium in eyes with age-related macular degeneration," Investigative Ophthalmology and Visual Science, vol. 37, no. 13, pp. 2724-2735, 1996.

[14] R. Amin, J. E. Puklin, and R. N. Frank, "Growth factor localization in choroidal neovascular membranes of agerelated macular degeneration," Investigative Ophthalmology and Visual Science, vol. 35, no. 8, pp. 3178-3188, 1994.

[15] D. W. Dawson, O. V. Volpert, P. Gillis et al., "Pigment epithelium-derived factor: a potent inhibitor of angiogenesis," Science, vol. 285, no. 5425, pp. 245-248, 1999.

[16] T. Ishibashi, Y. Hata, H. Yoshikawa, K. Nakagawa, K. Sueishi, and H. Inomata, "Expression of vascular endothelial growth factor in experimental choroidal neovascularization," Graefe's Archive for Clinical and Experimental Ophthalmology, vol. 235, no. 3, pp. 159-167, 1997.

[17] D. S. Goodsell, "The molecular perspective: VEGF and angiogenesis," Oncologist, vol. 7, no. 6, pp. 569-570, 2002.

[18] T. Matsumoto and L. Claesson-Welsh, "VEGF receptor signal transduction.," Science's STKE, vol. 2001, no. 112, p. re21, 2001.

[19] Z. Ablonczy, A. Prakasam, J. Fant, A. Fauq, C. Crosson, and K. Sambamurti, "Pigment epithelium-derived factor maintains retinal pigment epithelium function by inhibiting vascular endothelial growth factor-R2 signaling through $\gamma$-secretase," Journal of Biological Chemistry, vol. 284, no. 44, pp. 3017730186, 2009.

[20] N. Ferrara, K. Mayo, J. Cidlowski, N. Kochupillai, and G. Cutler, "Vascular endothelial growth factor and the regulation of angiogenesis," Recent Progress in Hormone Research, vol. 55, pp. 15-36, 2000.

[21] T. Qian and Z. Cai, "Biotransformation of ginsenosides Rb1, $\mathrm{Rg} 3$ and Rh2 in rat gastrointestinal tracts," Chinese Medicine, vol. 5, article 19, 2010.

[22] J. F. Cui, M. Garle, I. Björkhem, and P. Eneroth, "Determination of aglycones of ginsenosides in ginseng preparations sold in Sweden and in urine samples from Swedish athletes consuming ginseng," Scandinavian Journal of Clinical and Laboratory Investigation, vol. 56, no. 2, pp. 151-160, 1996.

[23] F. He, R. Guo, S. L. Wu, M. Sun, and M. Li, "Protective effects of ginsenoside Rb1 on human umbilical vein endothelial cells in vitro," Journal of Cardiovascular Pharmacology, vol. 50, no. 3, pp. 314-320, 2007.

[24] S. Sengupta, S. A. Toh, L. A. Sellers et al., "Modulating angiogenesis: the yin and the yang in ginseng," Circulation, vol. 110, no. 10, pp. 1219-1225, 2004.

[25] H. Y. Ji, H. W. Lee, H. K. Kim et al., "Simultaneous determination of ginsenoside Rb1 and Rg 1 in human plasma by liquid chromatography-mass spectrometry," Journal of Pharmaceutical and Biomedical Analysis, vol. 35, no. 1, pp. 207-212, 2004.

[26] J. G. Grigsby, K. Parvathaneni, M. A. Almanza et al., "Effects of tamoxifen versus raloxifene on retinal capillary endothelial cell proliferation," Journal of Ocular Pharmacology and Therapeutics, vol. 27, no. 3, pp. 225-233, 2011.

[27] J. Harmey, Ed., VEGF and Cancer, Landes Bioscience, Georgetown, Tex, USA, 2004.

[28] J. Harmey, Ed., VEGF and Cancer, vol. 1, Landes Bioscience, Georgetown, Tex, USA, 2004.

[29] A. R. Rudnicka and J. Birch, Diabetic Eye Disease, Butterworth/Heinemann, Oxford, UK, 1st edition, 2000. 


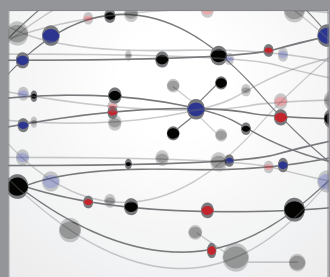

The Scientific World Journal
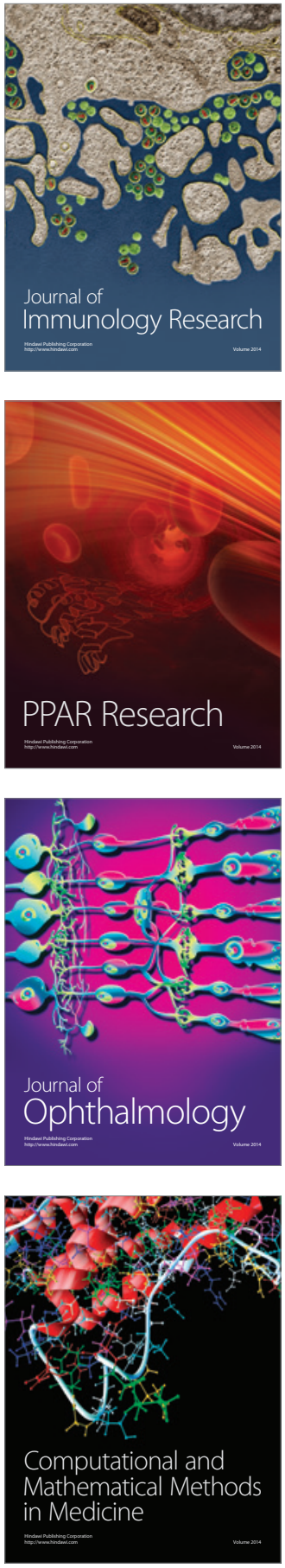

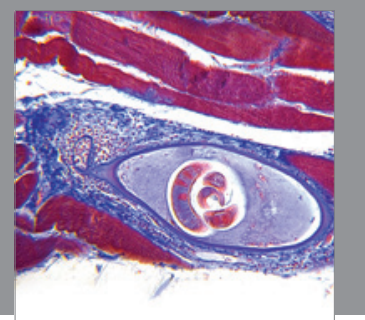

Gastroenterology

Research and Practice
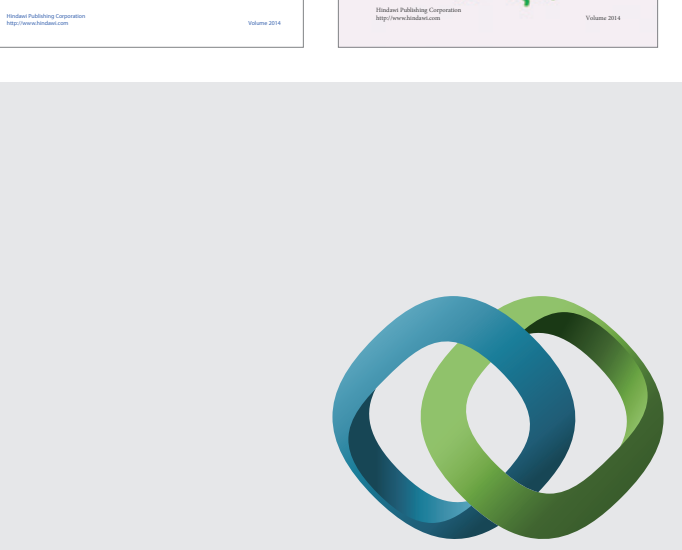

\section{Hindawi}

Submit your manuscripts at

http://www.hindawi.com
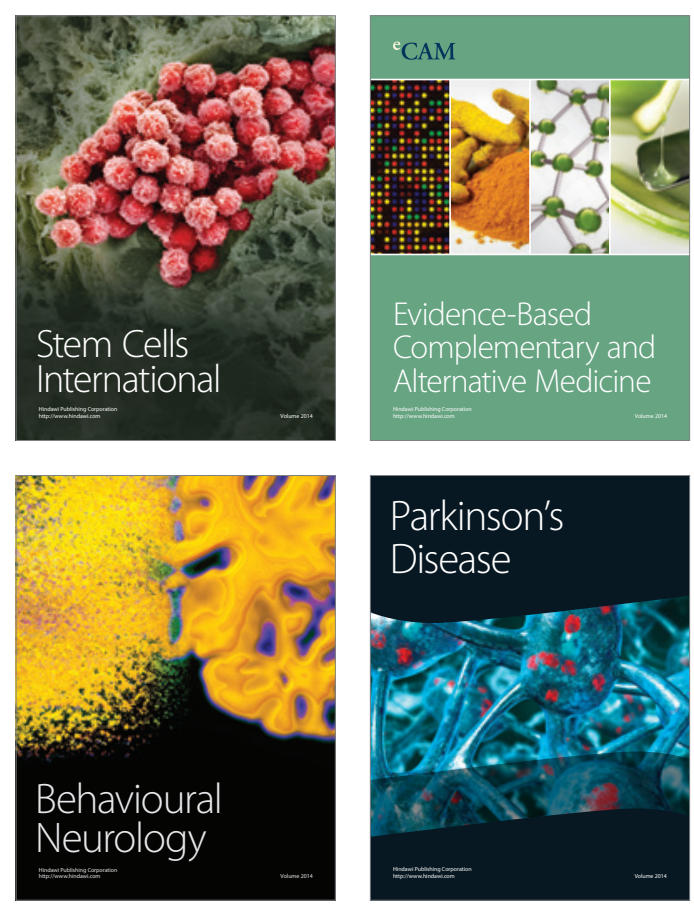

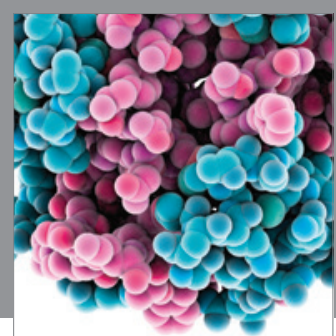

Journal of
Diabetes Research

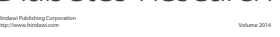

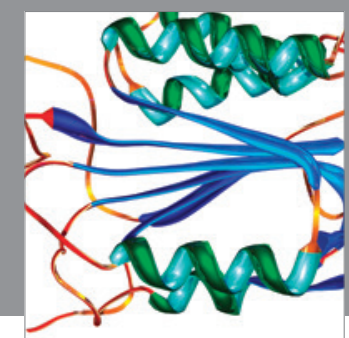

Disease Markers
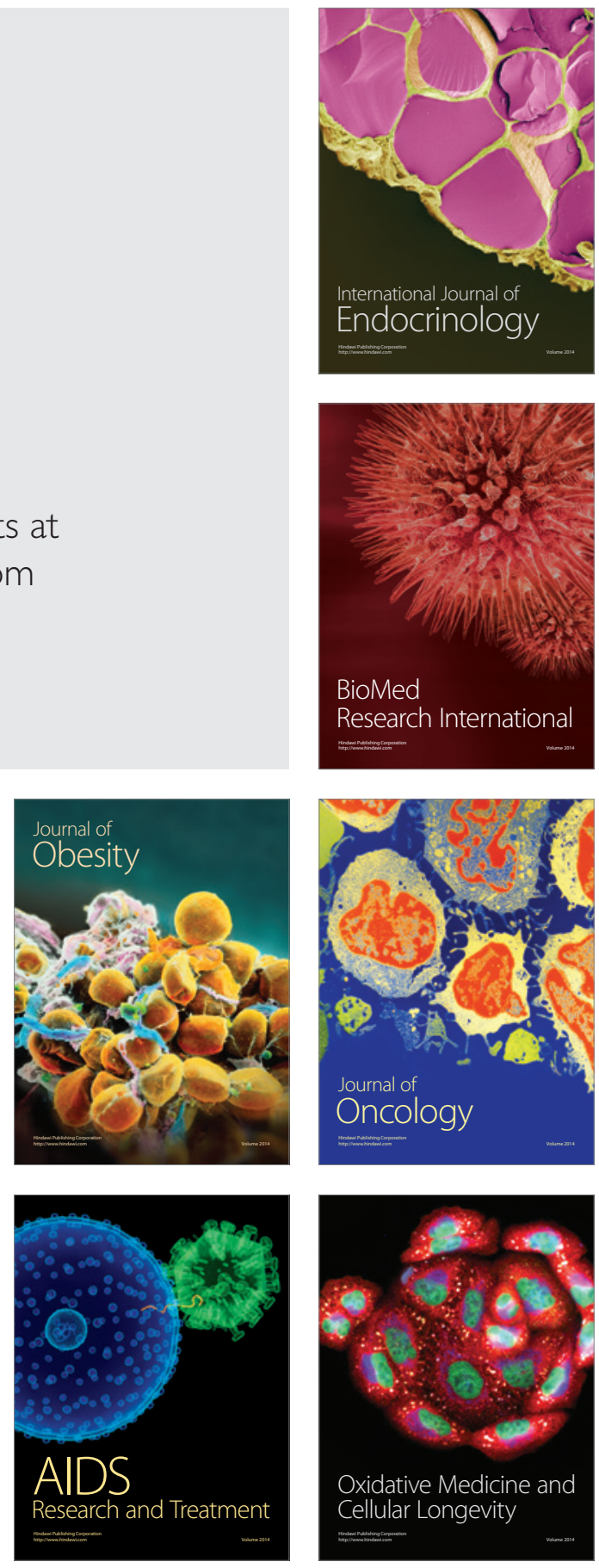